\title{
COMUNICAÇÃO
}

\section{CONTROLE GENÉTICO DA INCOMPATIBILIDADE DO CRUZAMENTO ENTRE CULTIVARES ANDINAS E MESOAMERICANAS DE FEIJOEIRO COMUM}

\author{
Genetic control of incompatibility in crosses of andean and mesoamerican \\ common bean cultivars
}

\author{
Lúcio de Oliveira Arantes¹, Magno Antonio Patto Ramalho², Ângela de Fátima Barbosa Abreu ${ }^{3}$
}

\begin{abstract}
RESUMO
Normalmente, ocorre incompatibilidade nos cruzamentos entre feijoeiros de origem andina com mesoamericanas. Há dúvidas no controle genético do caráter. Singh \& Gutiérrez (1984) relataram que no controle do caráter estão envolvidos dois genes e ocorre epistasia recessiva dupla. Vilarinho (2004) apresentou resultados, relatando que não seriam apenas dois genes. Para melhor elucidar o controle genético desse caráter foi realizado o presente trabalho. Para isso, a cultivar de origem andina 'Jalo EEP 558' foi cruzada com a 'Small White', que é mesoamericana, porém compatível com a anterior. A cultivar de origem mesoamericana 'Mulatinho da Vagem Roxa' também foi cruzada com a 'Small White'. As gerações $\mathrm{F}_{1}$ desses dois híbridos foram cruzadas entre si. As sementes resultantes foram semeadas no campo e avaliada a ocorrência ou não da incompatibilidade. Constatou-se a segregação de três plantas normais para uma incompatível. Esse resultado evidencia que são dois genes, $\mathrm{DL}_{1}$ e $\mathrm{DL}_{2}$, e que o genótipo das cultivares envolvidas são: 'Jalo EEP 558' $\mathrm{dl}_{1} \mathrm{dl}_{1} \mathrm{DL}_{2} \mathrm{DL}_{2}$; 'Mulatinho da Vagem Roxa' $\mathrm{DL}_{1} \mathrm{DL}_{1} \mathrm{dl}_{2} \mathrm{dl}_{2}$; 'Small White' $\mathrm{dl}_{1} \mathrm{dl}_{1} \mathrm{dl}_{2} \mathrm{dl}_{2}$.
\end{abstract}

Termos para indexação: Phaseolus vulgaris L., epistasia, genes.

\section{ABSTRACT}

Crosses between Andean and Mesoamerican common beans are usually incompatible. There are doubts about the genetic control of the trait. Singh \& Gutiérrez (1984) reported that two genes are involved in the trait control and that double recessive epistasis occurs. On the other hand, Vilarinho (2004) presented results indicating that more than two genes are involved. The present study was carried out to clarify the genetic control of this trait. For this purpose, the Andean cultivar 'Jalo EEP 558' was crossed with 'Small White', which is Mesoamerican, but compatible with the former one. The Mesoamerican cultivar 'Mulatinho da Vagem Roxa' was also crossed with 'Small White'. The $\mathrm{F}_{1}$ generation of these two hybrids was crossed with each other. The resulting seeds were sown on the field and the occurrence of incompatibility was evaluated. Segregation of 3 (normal) to 1 (incompatible) plants was observed, indicating that there are two genes, $\mathrm{DL}_{1}$ and $\mathrm{DL}_{2}$, as reported by Singh \& Gutiérrez (1984), and that the genotype of the cultivars involved are: 'Jalo EEP 558' $\mathrm{dl}_{1} \mathrm{dl}_{1} \mathrm{DL}_{2} \mathrm{DL}_{2}$; 'Mulatinho da Vagem Roxa' $\mathrm{DL} \mathrm{LL}_{1} \mathrm{dl}_{2} \mathrm{dl}_{2}$; 'Small White' $\mathrm{dl}_{1} \mathrm{dl}_{1} \mathrm{dl}_{2} \mathrm{dl}_{2}$.

Index terms: Phaseolus vulgaris L., epistasis, genes.

(Recebido em 17 de outubro de 2006 e aprovado em 22 de fevereiro de 2007)

Durante o processo de domesticação do feijoeirocomum (Phaseolus vulgaris L.), em consequência do isolamento geográfico, ocorreu a formação de conjuntos gênicos adaptados às diferentes condições ambientais, sendo o andino e o mesoamericano os principais (HANNAH et al., 2000; VIEIRA et al., 2005). O conjunto andino é caracterizado, principalmente, por feijões de grãos grandes e faseolina $\mathrm{T}, \mathrm{C}, \mathrm{H}$ e $\mathrm{A}$, enquanto que os mesoamericanos possuem sementes pequenas e phaseolina S (GEPTS \& DEBOUCK, 1991). Além disso, esses conjuntos diferem em várias outras características morfológicas e de resistência a patógenos, o que despertou o interesse dos melhoristas na utilização de hibridações inter "pools" gênicos. Contudo, o aproveitamento de uma maior divergência genética por meio do cruzamento entre cultivares andinas e mesoamericanas, em inúmeras situações, não é possível em consequência da ocorrência de incompatibilidade genética manifestada nas plantas da geração $\mathrm{F}_{1}$ (VIEIRA et al., 2005). Essa incompatibilidade se manifesta em nanismo ou fraqueza do híbrido $\mathrm{F}_{1}$, cujas

\footnotetext{
'Engenheiro Agrônomo, Mestrando em Genética e Melhoramento de Plantas - Departamento de Biologia/DBI - Universidade Federal de Lavras/UFLA Cx.P. 3037 - 37200-000 - Lavras, MG - lucio_arantes@yahoo.com.br

${ }^{2}$ Engenheiro Agrônomo, Doutor em Genética e Melhoramento de Plantas, Professor Titular - Departamento de Biologia/DBI - Universidade Federal de Lavras/UFLA - Cx. P. 3037 - 37200-000 - Lavras, MG - magnoapr@ufla.br

3Engenheira Agrônoma, Doutora em Genética e Melhoramento de Plantas - Embrapa Arroz e Feijão/UFLA - Departamento de Biologia/DBI - Universidade Federal de Lavras/UFLA - Cx. P. 3037 - 37200-000 - Lavras, MG - afbabreu@ufla.br
} 
plantas morrem ou têm fraco crescimento, exibindo diversas alterações, como esterilidade, crescimento radicular reduzido, folhas cloróticas, ausência de raízes, formação de raízes adventícias na região do hopocótilo e outras anormalidades (VIEIRA et al., 2005; VILARINHO, 2004).

A ocorrência da incompatibilidade foi relatada pela primeira vez por Davis \& Frazier (1964). Como a planta $\mathrm{F}_{1}$ é estéril, é difícil obter informações a respeito do controle genético. De acordo com Singh \& Gutierrez (1984), a incompatibilidade seria governada por dois genes, sendo um exemplo de epistasia recessiva dupla. As plantas andinas teriam o genótipo $\mathrm{dl}_{1} \mathrm{dl}_{1} \mathrm{DL}_{2} \mathrm{DL}_{2} \mathrm{e}$ as mesoamericanas $\mathrm{DL}_{1} \mathrm{DL}_{1} \mathrm{dl}_{2} \mathrm{dl}_{2}$. Na geração $\mathrm{F}_{1}$, o genótipo seria $\mathrm{DL}_{1} \mathrm{dl}_{1} \mathrm{DL}_{2} \mathrm{dl}_{2}$, ou seja, a presença dos alelos dominantes dos dois genes, ocorrendo a incompatibilidade.

Contudo, Vilarinho (2004) questionou se apenas dois genes estariam presentes nos cruzamentos envolvidos. Para explicar a segregação obtida por ela, foi proposta a existência de um terceiro gene. Cultivares mesoamericanas seriam $\mathrm{Dl}_{1} \mathrm{Dl}_{1} \mathrm{dl}_{2} \mathrm{dl}_{2} \mathrm{DL}_{3} \mathrm{DL}_{3} \mathrm{e}$ as andinas $\mathrm{dl}_{1} \mathrm{dl}_{1} \mathrm{DL}_{2} \mathrm{DL}_{2} \mathrm{dl}_{3} \mathrm{dl}_{3}$. Dessa forma, os alelos recessivos do gene $\mathrm{DL}_{3}$ agiriam conjuntamente com o alelo dominante do gene $\mathrm{DL}_{1}$. Sendo assim, plantas com genótipos $\mathrm{DL}_{1-} \mathrm{dl}_{3} \mathrm{dl}_{3}$ não seriam viáveis.

Para melhor elucidar o controle genético envolvido, a principal opção é utilizar uma cultivar que seja compatível, tanto com feijões andinos como mesoamericanos, ou seja, utilizar essas cultivares como "ponte". Desse modo, as gerações $F_{1}$ seriam férteis, possibilitando a obtenção de uma geração segregante para se estudar o controle genético.

Diante do exposto, neste trabalho, objetivou-se elucidar o controle genético da incompatibilidade do feijoeiro por meio da segregação obtida no cruzamento entre linhagens andinas com mesoamericanas, utilizandose uma cultivar "ponte".

Foram utilizadas as linhagens incompatíveis 'Jalo EEP', de origem andina, e a mesoamericana 'Mulatinho da Vagem Roxa'. Para possibilitar o cruzamento entre elas foi utilizada como ponte a cultivar 'Small White', mesoamericana, que não apresenta incompatibilidade. Os cruzamentos foram realizados em casa de vegetação, no Departamento de Biologia da Universidade Federal de Lavras, obtendo-se a geração $F_{1}$ entre 'Mulatinho da Vagem Roxa' x 'Small White' $\left(F_{1 \mathrm{~A}}\right)$ e 'Jalo EEP' $x$ 'Small White' $\left(F_{1 B}\right)$. Em seguida, cruzou-se $F_{1 A}$ com $F_{1 B}$, obtendo-se sementes " $\mathrm{F}_{1 \mathrm{AB}}$ ". As sementes obtidas foram semeadas a campo em novembro de 2005. Visando a detectar possíveis sintomas de incompatibilidade, as plantas foram avaliadas semanalmente, sendo que nas duas primeiras semanas esse acompanhamento não excedeu a dois dias.

Foi observado que o caráter "incompatibilidade" possui expressividade muito variável, o que dificulta a classificação fenotípica do mesmo, precocemente. Dentre as plantas incompatíveis, houve variação no estádio de desenvolvimento no qual se manifestaram os sintomas, observados desde a primeira semana até aproximadamente 40 dias após a semeadura. De acordo com Shii et al. (1980), esse caráter é influenciado pelo ambiente e, em temperaturas elevadas, as anormalidades morfológicas ocorridas em cruzamentos incompatíveis são acentuadas. Como no presente trabalho, as temperaturas máximas diárias foram superiores a $30^{\circ} \mathrm{C}$, contribuíram para facilitar a expressão do caráter. Foram observados sintomas típicos inerentes à fraqueza do híbrido $\mathrm{F}_{1}$, como nanismo, crescimento de raízes adventícias, folhas encarquilhadas e/ou cloróticas, entre outros.

Como era esperado, considerando apenas os genes $\mathrm{DL}_{1}$ e $\mathrm{DL}_{2}$, na geração $\mathrm{F}_{1 \mathrm{~A}}$ e $\mathrm{F}_{1 \mathrm{~B}}$ foram observadas plantas com morfologia normal e férteis. Já no cruzamento $\mathrm{F}_{1 \mathrm{~A}} \times \mathrm{F}_{1 \mathrm{~B}}=\mathrm{F}_{1 \mathrm{AB}}$, ocorreu segregação que se ajustou à proporção de três plantas normais para uma com nanismo (Tabela 1). Do exposto, $\mathrm{F}_{1 \mathrm{~A}}$ teria o genótipo $\mathrm{DL}_{1} \mathrm{dl}_{1} \mathrm{dl}_{2} \mathrm{dl}_{2} \mathrm{e}$ o $\mathrm{F}_{1 \mathrm{~B}}$ teria $\mathrm{dl}_{1} \mathrm{dl}_{1} \mathrm{DL}_{2} \mathrm{dl}_{2}$. Já o híbrido $\mathrm{F}_{1 \mathrm{AB}}$ apresentaria os genótipos $\mathrm{DL}_{1} \mathrm{dl}_{1} \mathrm{DL}_{2} \mathrm{dl}_{2}$ (nanismo), $\mathrm{DL}_{1} \mathrm{dl}_{1} \mathrm{dl}_{2} \mathrm{dl}_{2}$ (normal), $\mathrm{dl}_{1} \mathrm{dl}_{1} \mathrm{DL}_{2} \mathrm{dl}_{2}$ (normal) e $\mathrm{dl}_{1} \mathrm{dl}_{1} \mathrm{dl}_{2} \mathrm{dl}_{2}$ (normal), todos na mesma frequência de $1 / 4$ (Tabela 2 ). Fica, assim, evidente que devem estar envolvidos dois genes e a discrepância, em algumas situações, como observado por Vilarinho (2004), pode ser atribuída à diferenças na penetrância e expressividade dos genes em consequência do efeito ambiental, o que alteraria as segregações esperadas (RAMALHO et al., 2004).

Tabela 1 - Freqüência observada e esperada de plantas normais e incompatíveis na geração $\mathrm{F}_{1 \mathrm{AB}}$ do cruzamento entre as gerações $\mathrm{F}_{1}$ provenientes do cruzamento entre as cultivares Mulatinho da Vagem Roxa x Small White $\left(\mathrm{F}_{1 \mathrm{~A}}\right)$ e Jalo EEP x Small White $\left(\mathrm{F}_{1 \mathrm{~B}}\right)$.

\begin{tabular}{lccc}
\hline Fenótipos & $\begin{array}{c}\text { Frequência } \\
\text { Observada } \\
(\mathrm{FO})\end{array}$ & $\begin{array}{c}\text { Frequência } \\
\text { Esperada }^{1} \\
(\mathrm{FE})\end{array}$ & $\begin{array}{c}X^{2} \\
(\mathrm{FO}-\mathrm{FE})^{2} / \mathrm{FE}\end{array}$ \\
\hline Compatíveis & 122 & 126,75 & 0,18 \\
Incompatíveis & 47 & 42,25 & 0,53 \\
\hline & & & $0,71(\mathrm{P}=0,40)$ \\
\hline
\end{tabular}

${ }^{1}$ Considerando a segregação de 3:1. 
Tabela 2 - Genótipos para a reação de compatibilidade propostos para as cultivares de feijoeiro e híbridos $\mathrm{F}_{1}$.

\begin{tabular}{ll}
\hline \multicolumn{1}{c}{ Cultivares/híbridos } & \multicolumn{1}{c}{ Genótipos } \\
\hline Small White & $\mathrm{dl}_{1} \mathrm{dl}_{1} \mathrm{dl}_{2} \mathrm{dl}_{2}$ \\
Jalo EEP & $\mathrm{dl}_{1} \mathrm{dl}_{1} \mathrm{DL}_{2} \mathrm{DL}_{2}$ \\
Mulatinho Vagem Roxa & $\mathrm{DL}_{1} \mathrm{DL}_{1} \mathrm{dl}_{2} \mathrm{dl}_{2}$ \\
$\mathrm{~F}_{1 \mathrm{~A}}$ (Mulatinho Vagem Roxa x Small White) & $\mathrm{DL}_{1} \mathrm{dl}_{1} \mathrm{dl}_{2} \mathrm{dl}_{2}$ \\
$\mathrm{~F}_{1 \mathrm{~B}}$ (Jalo EEP x Small White) & $\mathrm{dl}_{1} \mathrm{dl}_{1} \mathrm{DL}_{2} \mathrm{dl}_{2}$ \\
$\mathrm{~F}_{1 \mathrm{AB}}$ & $1 / 4 \mathrm{DL}_{1} \mathrm{dl}_{1} \mathrm{DL}_{2} \mathrm{dl}_{2} ; 1 / 4 \mathrm{dl}_{1} \mathrm{dl}_{1} \mathrm{DL}_{2} \mathrm{dl}_{2} ;$ \\
& $1 / 4 \mathrm{DL}_{1} \mathrm{dl}_{1} \mathrm{dl}_{2} \mathrm{dl}_{2} ; 1 / 4 \mathrm{dl}_{1} \mathrm{dl}_{1} \mathrm{dl}_{2} \mathrm{dl}_{2}$ \\
\hline
\end{tabular}

\section{REFERÊNCIAS BIBLIOGRÁFICAS}

DAVIS, D. W.; FRAZIER, W. A. The incidence of three abnormalities in $\mathrm{F}_{2}$ progeny of crosses between two bushes and Blue Lake derived bush snap beans. Annual Report of the Bean Improvement Cooperative, Fort Collins, v. 7, p. 14-16, 1964.

GEPTS, P.; DEBOUCK, D. G. Origin, domestication, and evolution of the common bean, Phaseolus vulgaris. In: SCHOONHOVEN, A. van; VOYSEST, O. (Eds.). Common beans: research for crop improvement. Cali: CIAT, 1991. p. 7-53.

HANNAH, M. A.; IQBAL, M. J.; SANDERS, F. E. The DL gene system in common bean: a possible mechanism for control of root-shoot partitioning. New Phytologyst, Lancaster, v. 147, p. 487-496, 2000.

RAMALHO, M. A. P.; SANTOS, J. B. dos; PINTO, C. A. B. P. Genética na agropecuária. Lavras: UFLA, 2004. 472 p.
SHII, C. T.; MOK, M. C.; TEMPLE, S. R.; MOK, D. W. S. Expression of developmental abnormalities in hybrids of Phaseolus vulgaris L.: interaction between temperature and allelic dosage. The Journal of Heredity, Cary, v. 71, p. 218-222, 1980.

SINGH, S. P.; GUTIERREZ, J. A. Geographical distribution of the $\mathrm{DL}_{1}$ and $\mathrm{DL}_{2}$ genes causing hybrid dwarfism in Phaseolus vulgaris L., their association with seed size, and their significance to breeding. Euphytica, Wageningen, v. 33, p. 337-345, 1984.

VIEIRA, C.; BORÉM, A.; RAMALHO, M. A. P.; CARNEIRO, J. E. de S. Melhoramento do feijão. In: BORÉM, A. (Ed.). Melhoramento de espécies cultivadas. 2. ed. Viçosa: UFV, 2005. p. 301-391.

VILARINHO, L. B. O. Cultivares-ponte de feijoeiro, resistência à mancha-angular e mapeamento de QTLs. 2004. 81 f. Tese (Doutorado em Genética e Melhoramento de Plantas) - Universidade Federal de Viçosa, Viçosa, 2004. 